\title{
COPD advances in left ventricular diastolic dysfunction
}

\author{
This article was published in the following Dove Press journal: \\ International Journal of COPD \\ 29 March 2016 \\ Number of times this article has been viewed
}

\author{
Yoshiaki Kubota' \\ Kuniya Asai' \\ Koji Murai' \\ Yayoi Tetsuou Tsukada' \\ Hiroki Hayashi \\ Yoshinobu Saito ${ }^{2}$ \\ Arata Azuma ${ }^{2}$ \\ Akihiko Gemma ${ }^{2}$ \\ Wataru Shimizu' \\ 'Department of Cardiovascular \\ Medicine, ${ }^{2}$ Department of Pulmonary \\ Medicine and Oncology, Graduate \\ School of Medicine, Nippon Medical \\ School, Tokyo, Japan
}

Background: COPD is concomitantly present in $\sim 30 \%$ of patients with heart failure. Here, we investigated the pulmonary function test parameters for left ventricular (LV) diastolic dysfunction and the relationship between pulmonary function and LV diastolic function in patients with COPD.

Patients and methods: Overall, 822 patients who underwent a pulmonary function test and echocardiography simultaneously between January 2011 and December 2012 were evaluated. Finally, 115 patients with COPD and 115 age- and sex-matched control patients with an LV ejection fraction of $\geq 50 \%$ were enrolled.

Results: The mean age of the patients was $74.4 \pm 10.4$ years, and $72.3 \%$ were men. No significant differences were found between the two groups regarding comorbidities, such as hypertension, diabetes mellitus, and anemia. The index of LV diastolic function $\left(E / e^{\prime}\right)$ and the proportion of patients with high $E / e^{\prime}$ (defined as $E / e^{\prime} \geq 15$ ) were significantly higher in patients with COPD than in control patients $(10.5 \%$ vs $9.1 \%, P=0.009 ; 11.3 \%$ vs $4.3 \%, P=0.046)$. E/ $e^{\prime}$ was significantly correlated with the residual volume/total lung capacity ratio. Univariate and multivariate analyses revealed severe COPD (Global Initiative for Chronic Obstructive Lung Disease III or IV) to be a significant predictive factor for high $E / e^{\prime}$ (odds ratio [OR] 5.81, 95\% confidence interval [CI] 2.13-15.89, $P=0.001$ and OR 6.00, 95\% CI 2.08-17.35, $P=0.001$, respectively). Conclusion: Our data suggest that LV diastolic dysfunction as a complication of COPD may be associated with mechanical exclusion of the heart by pulmonary overinflation.

Keywords: COPD, heart failure, left ventricular diastolic dysfunction

\section{Introduction}

COPD is a systemic inflammatory disease characterized by airflow limitation that is not fully reversible. ${ }^{1}$ COPD is complicated by a high rate of cardiac diseases ${ }^{2}$ and is present in approximately one-third of patients with congestive heart failure (HF). ${ }^{3,4}$ Patients with HF with preserved ejection fraction ( $\mathrm{pEF}$ ) are more likely to have a history of COPD compared with patients with HF with reduced ejection fraction. ${ }^{5}$ A proposed paradigm for $\mathrm{pEF}$ in patients with $\mathrm{HF}$ identifies a systemic proinflammatory state induced by comorbidities, such as COPD, diabetes mellitus (DM), hypertension (HTN), and obesity. This proinflammatory state leads to structural and functional myocardial alterations via increased oxidative stress in the vascular endothelium. ${ }^{6}$ Previous studies have examined the relationship between forced expiratory volume and heart disease. Barr et $\mathrm{al}^{7}$ found that an impaired endothelial function was associated with low forced expiratory volume in 1 second $\left(\mathrm{FEV}_{1}\right)$ and high-resolution computed tomography percentage of emphysema in former smokers early in COPD. In a population-based study, a greater extent of emphysema on computed tomography and more severe airflow obstruction were linearly related to impaired left ventricular
Correspondence: Yoshiaki Kuobota Department of Cardiovascular Medicine, Nippon Medical School, I-I-5, Sendagi, Bunkyo-ku, Tokyo II 3-0022, Japan Email ykubota@nms.ac.jp
International Journal of COPD 2016: I | 649-655

Dovepress

http://dx.doi.org/10.2147/COPD.S101082 (c) (i) (\$) 2016 Kubota et al. This work is published and licensed by Dove Medical Press Limited. The full terms of this license are available at https://www.dovepress.com/terms.php cc) and incorporate the Creative Commons Attribution - Non Commercial (unported, v3.0) License (http://creativecommons.org/licenses/by-nc/3.0/). By accessing the work you hereby accept the Terms. Non-commercial uses of the work are permitted without any further permission from Dove Medical Press Limited, provided the work is properly attributed. For permission for commercial use of this work, please see paragraphs 4.2 and 5 of our Terms (https://www.dovepress.com/terms.php). 
(LV) filling, reduced stroke volume, and lower cardiac output without changes in the ejection fraction. ${ }^{8}$ Hole et $\mathrm{al}^{9}$ found a significant inverse relationship between $\mathrm{FEV}_{1}$ and death due to ischemic heart disease and stroke. Previous Doppler studies have demonstrated that left ventricular diastolic dysfunction (LVDD) is frequently found in severe patients with COPD. ${ }^{10,11}$ However, these studies had a small sample size, excluded mild-to-moderate COPD, and did not use tissue Doppler echocardiography, which is more accurate than Doppler LV inflow study for detecting LVDD. According to the Heart Failure and Echocardiography Associations of the European Society of Cardiology, diagnostic evidence of diastolic LV dysfunction can be obtained noninvasively by tissue Doppler $\left(E / e^{\prime} \geq 15\right) .{ }^{12}$ Thus, here, we evaluated LV diastolic function using tissue Doppler echocardiography in mild-to-moderate patients with COPD.

Our objectives were to evaluate the incidences of LVDD among the COPD and control groups with respiratory failure, determine the relationship between pulmonary function test (PFT) parameters and LVDD $\left(E / e^{\prime}\right)$, and determine the predictive factor of a high $E / e^{\prime}$ (defined as $\left.E / e^{\prime} \geq 15\right)$ as an index of severe LVDD. ${ }^{12}$

\section{Patients and methods}

\section{Study design}

Overall, 822 consecutive patients who underwent both PFT and echocardiography simultaneously (within 3 months) for determining the cause of respiratory failure between January 2011 and December 2012 were evaluated (Figure 1). The age criterion was $\geq 20$ years. The exclusion criteria were presence of acute coronary syndromes $(\mathrm{n}=28)$, including acute myocardial infarction, end-stage renal disease requiring dialysis $(n=16)$, past history of acute decompensated HF $(n=48)$, or LV ejection fraction $<50 \%(\mathrm{n}=62)$. COPD was diagnosed according to the Global Initiative for Chronic Obstructive Lung Disease criteria. ${ }^{13}$ Finally, 115 patients with COPD and 115 age- and sexmatched control patients with an LV ejection fraction of $\geq 50 \%$ were enrolled. The control group included patients with interstitial pneumonia $(n=69)$, lung cancer $(n=13)$, tuberculosis $(n=9)$, and other diseases $(n=24)$. The health statuses of patients were obtained using electronic clinical records. This retrospective study was conducted using data from a large university hospital. The protocol used complied with the Declaration of Helsinki and was approved by our institutional ethics committee of Nippon Medical School, which waived the need for patient consent owing to the retrospective nature of the study.

\section{Relevant factors}

The heart rate and systolic blood pressure were simultaneously measured at rest using electrocardiography. Height and weight were measured at the time of PFT, and the body mass index $\left(\mathrm{kg} / \mathrm{m}^{2}\right)$ was calculated as an index of obesity. HTN was defined as systolic blood pressure $\geq 140 \mathrm{mmHg}$, diastolic blood pressure $\geq 90 \mathrm{mmHg}$, or current use of antihypertensive agents. DM was defined as fasting plasma glucose level $\geq 126.0 \mathrm{mg} / \mathrm{dL}$ and 2-hour plasma glucose level $>200 \mathrm{mg} / \mathrm{dL}$ during an oral glucose tolerance test or current treatment with antidiabetic agents. ${ }^{14}$

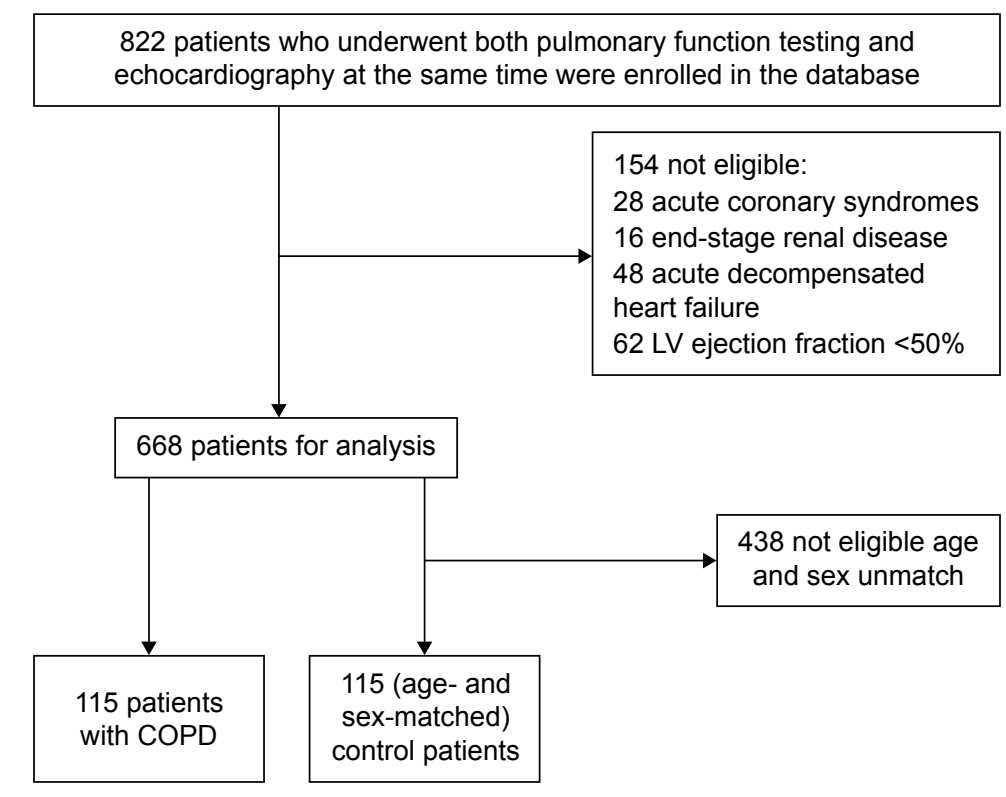

Figure I Inclusion criteria for the study population. Abbreviation: LV, left ventricular. 
Anemia was defined as hemoglobin level $<13 \mathrm{~g} / \mathrm{dL}$ in men and $<12 \mathrm{~g} / \mathrm{dL}$ in women. Chronic kidney disease (CKD) was defined as glomerular filtration rate $\leq 60 \mathrm{~mL} / \mathrm{min} / 1.73 \mathrm{~m}^{2}$; this value was estimated using the simplified prediction equation derived from the Modification of Diet in Renal Disease study. ${ }^{15}$ Clinical data were obtained from PFTs or echocardiography when the hemodynamic conditions of the patients had stabilized.

\section{Echocardiography parameters}

Transthoracic echocardiography was recorded using an iE33 system (Philips Medical Systems, Bothell, WA, USA). We conducted standard, comprehensive, motion-mode (M-mode), two-dimensional echocardiography and Doppler studies according to the American Society of Echocardiography guidelines. ${ }^{16}$ The left auricle diameter, left ventricle end-systolic and end-diastolic diameters, interventricular septal thickness, and posterior wall thickness were measured using M-mode echocardiography from the left parasternal short- and long-axis views. The LV ejection fraction was calculated using the modified Simpson's method. The tricuspid regurgitation velocity was obtained by continuous wave Doppler imaging from the right ventricular inflow or the apical four-chamber view position. The transtricuspid pressure gradient (TRPG) was calculated as follows:

$$
\mathrm{TRPG}=4 \times \text { tricuspid regurgitation velocity }{ }^{2}
$$

The peak early diastolic phase $(E)$ and late diastolic phase (A) mitral inflow velocities and the $E / A$ ratio were measured using pulsed-wave Doppler echocardiography with the sample volume between the mitral leaflet tips. The mitral annular velocity $\left(E^{\prime}\right)$ and mean $E / e^{\prime}$ ratio were measured at the septal and lateral annulus using tissue Doppler imaging.

\section{PFT}

Pre- and postbronchodilator PFTs were performed using CHSETAC-8900 (Nihon Kohden, Tokyo, Japan), according to the American Thoracic Society (ATS) guidelines. ${ }^{17} \mathrm{We}$ performed spirometry (forced vital capacity [FVC], $\mathrm{FEV}_{1}$, and the $\mathrm{FEV}_{1} / \mathrm{FVC}$ ratio) and plethysmography (total lung capacity [TLC], residual volume [RV], and the RV/TLC ratio). Spirometry quality was assessed according to the ATS/European Respiratory Society recommendations. ${ }^{18}$ COPD and COPD severity were defined according to the ATS/European Respiratory Society COPD criteria by using postbronchodilator measures of pulmonary function. ${ }^{19}$

\section{Statistical analyses}

The SPSS software package Version 20.0 (IBM Corporation, Armonk, NY, USA) was used for statistical analyses. All continuous values and categorical variables are expressed as mean \pm standard deviation and the number and percentage of patients, respectively. We compared the control and COPD groups using the unpaired $t$-test. The relationships between PFT parameters and LVDD were tested using Pearson's correlation. Univariate and multivariable logistic regression analyses were performed to identify potential risk factors for a high $E / e^{\prime}$. Age, sex, obesity, anemia, HTN, DM, atrial fibrillation (AF), COPD stage, anemia, and CKD had planned inclusion in the original model. To assess the robustness of the planned model, other potential factors among the baseline characteristics were considered for inclusion in the multivariate model by stepwise selection (significance level for inclusion 0.10). A two-sided probability value of $P<0.05$ was considered statistically significant.

\section{Results}

Table 1 shows the clinical characteristics of all patients. No significant differences were found between the COPD and

Table I Clinical characteristics of the study population

\begin{tabular}{llll}
\hline Variables & COPD $(\mathbf{n}=\mathbf{I}$ I5), mean \pm SD & Control $(\mathbf{n}=\mathbf{I}$ I5), mean \pm SD & $P$-value \\
\hline Age (years) & $74.4 \pm 10.3$ & $74.4 \pm 10.3$ & 1.000 \\
Male sex (\%) & 72.3 & 72.3 & 1.000 \\
BMI $\left(\mathrm{kg} / \mathrm{m}^{2}\right)$ & $21.5 \pm 4.3$ & $22.5 \pm 3.8$ & 0.060 \\
Hypertension (\%) & 55.4 & 45.5 & 0.143 \\
Diabetes mellitus (\%) & 20.5 & 25.0 & 0.428 \\
AF $(\%)$ & 14.3 & 8.0 & 0.139 \\
BNP $(\mathrm{Pg} / \mathrm{mL})$ & $118.6 \pm 76.5$ & $73.9 \pm 109.1$ & 0.062 \\
Hemoglobin (g/dL) & $12.3 \pm 3.1$ & $12.9 \pm 2.0$ & 0.155 \\
Creatinine (mg/dL) & $1.05 \pm 0.93$ & $0.88 \pm 0.34$ & 0.074 \\
CKD $(\%)$ & 38.4 & 41.1 & 0.684 \\
EF $(\%)$ & $67.1 \pm 9.2$ & $68.3 \pm 8.3$ & 0.292 \\
TRPG (mmHg) & $32.4 \pm 13.0$ & $34.7 \pm 18.9$ & 0.303 \\
Smoke (Brinkman index) & $1.147 .7 \pm 869.5$ & $625.3 \pm 839.5$ & $<0.001$ \\
\hline
\end{tabular}

Notes: Data presented as mean \pm SD unless otherwise indicated. $P$-value obtained using unpaired $t$-test.

Abbreviations: BMI, body mass index; AF, atrial fibrillation; BNP, brain-type natriuretic peptide; CKD, chronic heart disease; EF, ejection fraction; SD, standard deviation; TRPG, transtricuspid pressure gradient. 
Table 2 Echocardiography and pulmonary function test parameters of the study population

\begin{tabular}{|c|c|c|c|}
\hline Variables & COPD $(n=|| 5)$ & Control $(n=|| 5)$ & $P$-value \\
\hline \multicolumn{4}{|l|}{ Echocardiography } \\
\hline IVST (mm) & $9.4 \pm 2.2$ & $8.4 \pm 1.6$ & 0.183 \\
\hline PWT (mm) & $9.0 \pm 1.7$ & $8.2 \pm 1.4$ & 0.354 \\
\hline LVEDD (mL) & $87.8 \pm 31.2$ & $92.7 \pm 27.6$ & 0.228 \\
\hline LVESD (mL) & $28.4 \pm 16.9$ & $27.7 \pm 12.3$ & 0.751 \\
\hline $\mathrm{SV}(\mathrm{mL})$ & $59.4 \pm 19.1$ & $63.1 \pm 21.4$ & 0.181 \\
\hline $\mathrm{LAD}(\mathrm{mL})$ & $35.4 \pm 10.3$ & $34.3 \pm 8.3$ & 0.398 \\
\hline$E / A$ & $0.79 \pm 0.4 \mathrm{I}$ & $0.74 \pm 0.57$ & 0.396 \\
\hline E & $58.7 \pm 18.5$ & $53.3 \pm 16.3$ & 0.027 \\
\hline $\mathrm{e}^{\prime}$ (septal) & $5.9 \pm 1.7$ & $6.1 \pm 5.3$ & 0.779 \\
\hline $\mathrm{e}^{\prime}$ (lateral) & $7.7 \pm 2.3$ & $7.8 \pm 3.0$ & 0.747 \\
\hline Mean E/e' & $10.5 \pm 5.0$ & $9.1 \pm 2.7$ & 0.009 \\
\hline High E/e' (\%) & 11.3 & 4.3 & 0.046 \\
\hline \multicolumn{4}{|l|}{ Pulmonary function test } \\
\hline $\mathrm{FEV}_{1}(\mathrm{~L})$ & $1.33 \pm 0.70$ & $1.76 \pm 0.73$ & - \\
\hline $\mathrm{FVC}(\mathrm{L})$ & $2.46 \pm 0.93$ & $2.25 \pm 0.99$ & - \\
\hline FEV,/FVC ratio (\%) & $57.8 \pm 12.1$ & $79.9 \pm 13.1$ & - \\
\hline $\mathrm{RV}(\mathrm{L})$ & $2.09 \pm 0.68$ & $\mathrm{I} .44 \pm 0.64$ & - \\
\hline RV/TLC ratio (\%) & $45.3 \pm 10.4$ & $37.5 \pm 11.0$ & - \\
\hline
\end{tabular}

Notes: Data presented as mean \pm SD unless otherwise indicated. $P$-value obtained using unpaired $t$-test.

Abbreviations: IVST, interventricular septal thickness; PWT, posterior wall thickness; LVEDD, left ventricular end-diastolic diameter; LVESD, left ventricular end-systolic diameter; SV, stroke volume; LAD, left atrial dimension; FEV , forced expiratory volume in I second; FVC, forced vital capacity; RV, residual volume; TLC, total lung capacity.

control groups in terms of body mass index; prevalence of HTN, DM, AF, or CKD; brain natriuretic peptide levels; hemoglobin levels; LV ejection fraction; or TRPG. However, the COPD group had a significantly higher Brinkman index for smoking compared with the control group. In the COPD group, the COPD severity according to the global initiative was COPD I in 33 (28.7\%) patients, II in $42(36.5 \%)$ patients, III in $25(21.8 \%)$ patients, and IV in $15(13.0 \%)$ patients.

\section{Echocardiography and PFT parameters}

The echocardiography and PFT parameters of the two groups are shown in Table 2. $E$, mean $E / e^{\prime}$ ratio, and the

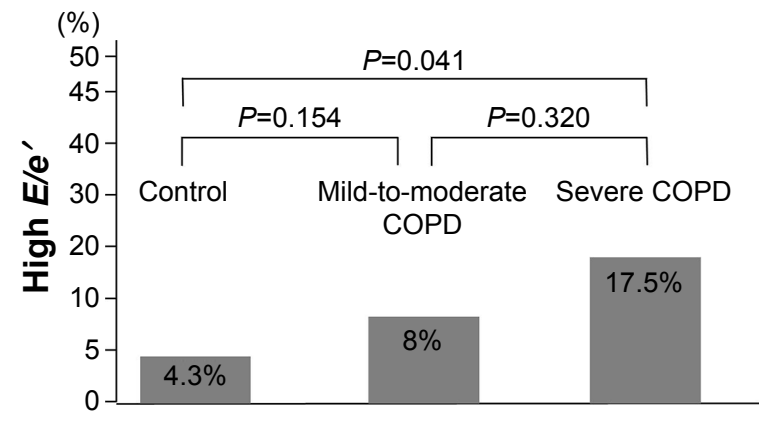

Figure 2 Proportion of high E/e' in each group.

Notes: Proportion of high E/e' was significantly higher in the severe COPD group (Global Initiative for Chronic Obstructive Lung Disease III or IV) than in the control group (I7.5\% vs $4.3 \%, P=0.04 I)$. However, no difference was found in the proportion of high E/e' between the severe COPD group and the mild-to-moderate COPD group (Global Initiative for Chronic Obstructive Lung Disease I or II; 17.5\% vs $8.0 \%, P=0.320)$. $P$-value obtained using unpaired $t$-test.

proportion of high $E / e^{\prime}$ as an index of severe LVDD were significantly higher in the COPD group than in the control group. The proportion of high $E / e^{\prime}$ was significantly higher in the severe COPD (Global Initiative for Chronic Obstructive Lung Disease III or IV) group than in the control group. However, no difference was found in the proportion of high $E / e^{\prime}$ between the severe COPD group and mild-to-moderate COPD (Global Initiative for Chronic Obstructive Lung Disease I or II) group (17.5\% vs $8.0 \%, P=0.320$; Figure 2). No significant differences were observed between the two groups regarding standard M-mode echocardiography parameters. The COPD group had a significantly lower $\mathrm{FEV}_{1}$ and $\mathrm{FEV}_{1} / \mathrm{FVC}$ ratio and a higher RV and RV/TLC ratio compared with the control group. The mean $E / e^{\prime}$ ratio was significantly negatively correlated with $\mathrm{FEV}_{1}$ and positively correlated with the RV/TLC ratio of PFT (Figure 3). However, no significant associations were found between other PFT parameters and the mean $E / e^{\prime}$ ratio (Table 3).

Univariate analysis revealed AF, severe COPD, and anemia to be significant predictive factors for high $E / e^{\prime}$, while

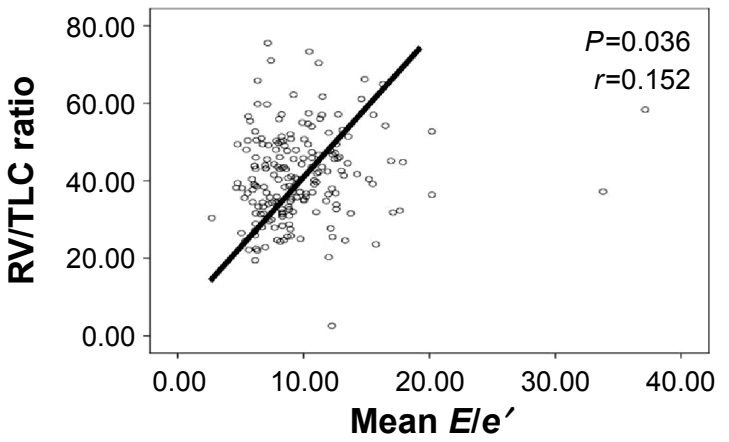

Figure 3 Correlation between mean E/e' and FEV, or RV/TLC ratio in all patients $(n=230)$.

Notes: Mean E/e' was significantly associated with FEV $(r=-0.263, P<0.00 \mathrm{I})$ and RV/TLC ratio $(r=0.152, P=0.036)$. $P$-value obtained using Pearson's correlation. Abbreviations: $\mathrm{FEV}_{1}$, forced expiratory volume in I second; RV, residual volume; TLC, total lung capacity. 
Table 3 The relationship between PFT parameters and mean E/e'

\begin{tabular}{|c|c|c|}
\hline \multirow[t]{2}{*}{ Variables } & \multicolumn{2}{|c|}{ Mean E/e' } \\
\hline & $R$ & $P$-value \\
\hline \multicolumn{3}{|l|}{ PFT } \\
\hline $\mathrm{FEV}_{1}(\mathrm{~L})$ & -0.263 & $<0.00$ I \\
\hline FVC (L) & -0.043 & 0.526 \\
\hline $\mathrm{FEV} / \mathrm{FVC}$ ratio (\%) & -0.018 & 0.791 \\
\hline $\mathrm{RV}(\mathrm{L})$ & 0.112 & 0.125 \\
\hline RV/TLC ratio (\%) & 0.152 & 0.036 \\
\hline Smoke (Brinkman index) & -0.089 & 0.190 \\
\hline
\end{tabular}

Note: $P$-value obtained using Pearson's correlation.

Abbreviations: PFT, pulmonary function test; $\mathrm{FEV}_{1}$, forced expiratory volume in I second; FVC, forced vital capacity; RV, residual volume; TLC, total lung capacity.

multivariate analysis revealed severe COPD and anemia to be significant predictive factors for high $E / e^{\prime}$ (Table 4).

\section{Discussion}

This study is a complete, noninvasive hemodynamic investigation of patients with COPD by using echocardiography and PFTs. Our evaluations of mitral inflow and mitral annular velocities confirmed changes in LVDD in patients with COPD compared with the control patients. A significant increase in the $E / e^{\prime}$ ratio was noted in the COPD group. We observed a weak but significant linear association of LVDD as measured by echocardiography, with both postbronchodilator $\mathrm{FEV}_{1}$ and the $\mathrm{RV} / \mathrm{TLC}$ ratio. Univariate and multivariate analyses revealed severe COPD to be a significant predictive factor for high $E / e^{\prime}$. Our data suggest that the cause for LVDD as a complication of COPD includes mechanical exclusion of the heart by pulmonary overinflation.

Many factors contribute to the underlying cause of LVDD in patients with COPD. First, hypoxia and a systemic proinflammatory state lead to atherosclerosis via increased oxidative stress in the vascular endothelium. ${ }^{6,7}$ Second, the severity of hypoxemia and pulmonary artery pressure or pulmonary vascular resistance has been reported to be closely in patients with COPD, indicating a major role in alveolar hypoxia. ${ }^{20-23}$ Alveolar hypoxia causes constriction of resistance pulmonary arteries, and sustained alveolar hypoxia induces pulmonary vascular remodeling. ${ }^{24}$ Pulmonary HTN is observed in half of the patients with severe COPD. ${ }^{25}$ Moreover, $\sim 25 \%$ of mildto-moderate patients with COPD without resting pulmonary HTN at onset will develop pulmonary HTN during a 6-year follow-up. ${ }^{26}$ Therefore, pulmonary HTN induced by pulmonary vascular remodeling may associate with the LVDD observed in patients with COPD. Third, we demonstrated that the mean $E / e^{\prime}$ ratio as a parameter of LVDD was significantly negatively correlated with $\mathrm{FEV}_{1}$ and positively correlated with the RV/TLC ratio of PFT. It may be explained to lead to mechanical exclusion of the heart by pulmonary overinflation. Hyperinflation in very severe patients with COPD can cause increased intrathoracic pressure and decreased venous pressure, with reductions in the blood volumes of both ventricles. ${ }^{27}$ Such ventricular interdependence can impair LV filling, causing the LVDD in patients with severe COPD ${ }^{10,28}$ and mild-to-moderate COPD. ${ }^{8}$ In this study, we demonstrated that severe COPD was a significant predictive factor for high $E / e^{\prime}$. As a result, hyperinflation may lead to LVDD.

\section{Study limitations}

The main limitations of this study were the relatively small sample size and the retrospective design. Moreover, the control group included patients with interstitial pneumonia, lung cancer, tuberculosis, and other diseases. Therefore, the control group may need to be limited to a generally healthy cohort in future studies. Previous data suggest that patients with HF with $\mathrm{pEF}$ tend to be older with a female predominance. ${ }^{5,29}$ Age is one of the most cited factors affecting LV filling. ${ }^{30}$ However, in this study, the control subjects and patients with COPD were age and sex matched. The COPD group had a significantly higher Brinkman index for smoking compared with that of the control group. Smoking itself may cause subclinical changes in the LV function. ${ }^{31}$ However, the Brinkman index did not significantly correlate with $E / e^{\prime}$ in our study. Hence, further prospective, large-scale clinical studies are needed.

Table 4 The odds ratio of prediction for high $E / e^{\prime}$

\begin{tabular}{lllll}
\hline Variables & Univariate $\mathbf{( 9 5 \% ~ C I )}$ & P-value & Multivariate $\mathbf{( 9 5 \% ~ C l )}$ & $P$-value \\
\hline Age $(>75$ years) & $2.26(0.78-6.58)$ & 0.134 & $2.47(0.62-6.48)$ & - \\
Male sex & $0.58(0.27-2.09)$ & 0.580 & - & - \\
Obesity & $1.10(0.35-3.55)$ & 0.863 & - & - \\
Hypertension & $1.60(0.60-4.30)$ & 0.349 & - & - \\
Diabetes mellitus & $0.94(0.30-3.00)$ & 0.920 & $2.63(0.75-9.17)$ & - \\
Atrial fibrillation & $3.50(1.13-10.84)$ & 0.030 & - & 0.130 \\
COPD (GOLD I or II) & $2.87(0.99-8.35)$ & 0.053 & $6.00(2.08-17.35)$ & - \\
COPD (GOLD III or IV) & $5.8 I(2.13-15.89)$ & 0.001 & $3.34(1.11-10.08)$ & 0.001 \\
Anemia & $3.39(1.22-9.40)$ & 0.019 & - & - \\
CKD & $2.03(0.77-5.36)$ & 0.154 & & -032 \\
\hline
\end{tabular}

Note: $P$-value obtained using univariate and multivariable logistic regression analyses.

Abbreviations: $\mathrm{Cl}$, confidence interval; GOLD, Global Initiative for Chronic Obstructive Lung Disease; CKD, chronic kidney disease. 


\section{Conclusion}

LVDD as a complication of COPD may be associated with mechanical exclusion of the heart by pulmonary overinflation. Performing PFT for patients with HF, timely diagnosis of COPD and further intervention therapy may lead to pathological improvement and a greater understanding of COPD.

\section{Acknowledgment}

The authors thank Dr Yukichi Tokita and Dr Masatomo Yoshikawa for their help in collecting patients' data.

\section{Disclosure}

The authors report no conflicts of interest in this work.

\section{References}

1. Fabbri LM, Luppi F, Beghé B, Rabe KF. Complex chronic comorbidities of COPD. Eur Respir J. 2008;31:204-212.

2. Divo M, Cote C, de Torres JP, et al. Comorbidities and risk of mortality in patients with chronic obstructive pulmonary disease. Am J Respir Crit Care Med. 2012;186:155-161.

3. Lainscak M, Cleland JG, Lenzen MJ, Follath F, Komajda M, Swedberg K. International variations in the treatment and co-morbidity of left ventricular systolic dysfunction: data from the EuroHeart Failure Survey. Eur J Heart Fail. 2007;9:292-299.

4. Hawkins NM, Petrie MC, Jhund PS, Chalmers GW, Dunn FG, McMurray JJ. Heart failure and chronic obstructive pulmonary disease: diagnostic pitfalls and epidemiology. Eur J Heart Fail. 2009;11: 130-139.

5. Bhatia RS, Tu JV, Lee DS, et al. Outcome of heart failure with preserved ejection fraction in a population-based study. $N$ Engl J Med. 2006;355:260-269.

6. Paulus WJ, Tschöpe C. A novel paradigm for heart failure with preserved ejection fraction: comorbidities drive myocardial dysfunction and remodeling through coronary microvascular endothelial inflammation. J Am Coll Cardiol. 2013;62:263-271.

7. Barr RG, Mesia-Vela S, Austin JH, et al. Impaired flow-mediated dilation is associated with low pulmonary function and emphysema in ex-smokers: the Emphysema and Cancer Action Project (EMCAP) Study. Am J Respir Crit Care Med. 2007;176:1200-1207.

8. Barr RG, Bluemke DA, Ahmed FS, et al. Percent emphysema, airflow obstruction, and impaired left ventricular filling. N Engl J Med. 2010; 362:217-227.

9. Hole DJ, Watt GC, Davey-Smith G, Hart CL, Gillis CR, Hawthorne VM. Impaired lung function and mortality risk in men and women: findings from the Renfrew and Paisley prospective population study. BMJ. 1996;313:711-715; discussion 715-716.

10. Boussuges A, Pinet C, Molenat F, et al. Left atrial and ventricular filling in chronic obstructive pulmonary disease. An echocardiographic and Doppler study. Am J Respir Crit Care Med. 2000;162:670-675.

11. Watz H, Waschki B, Boehme C, Claussen M, Meyer T, Magnussen H. Extrapulmonary effects of chronic obstructive pulmonary disease on physical activity: a cross-sectional study. Am J Respir Crit Care Med. 2008; 177:743-751.

12. Paulus WJ, Tschope C, Sanderson JE, et al. How to diagnose diastolic heart failure: a consensus statement on the diagnosis of heart failure with normal left ventricular ejection fraction by the Heart Failure and Echocardiography Associations of the European Society of Cardiology. Eur Heart J. 2007;28:2539-2550.
13. Rabe KF, Hurd S, Anzueto A, et al. Global strategy for the diagnosis, management, and prevention of chronic obstructive pulmonary disease: GOLD executive summary. Am J Respir Crit Care Med. 2007;176: $532-555$.

14. Diagnosis and classification of diabetes mellitus. Diabetes Care. 2014;37(Suppl 1):S81-S90.

15. Levey AS, Bosch JP, Lewis JB, et al. A more accurate method to estimate glomerular filtration rate from serum creatinine: a new prediction equation. Modification of Diet in Renal Disease Study Group. Ann Intern Med. 1999;130:461-470.

16. Schiller NB, Shah PM, Crawford M, et al. Recommendations for quantitation of the left ventricle by two-dimensional echocardiography. American Society of Echocardiography Committee on Standards, Subcommittee on Quantitation of Two-Dimensional Echocardiograms. J Am Soc Echocardiogr. 1989;2:358-367.

17. Standardization of Spirometry, 1994 Update. American Thoracic Society. Am J Respir Crit Care Med. 1995;152:1107-1136.

18. Miller MR, Crapo R, Hankinson J, et al. General considerations for lung function testing. Eur Respir J. 2005;26:153-161.

19. Celli BR, MacNee W. Standards for the diagnosis and treatment of patients with COPD: a summary of the ATS/ERS position paper. Eur Respir J. 2004;23:932-946.

20. Chaouat A, Naeije R, Weitzenblum E. Pulmonary hypertension in COPD. Eur Respir J. 2008;32:1371-1385.

21. Chatila WM, Thomashow BM, Minai OA, Criner GJ, Make BJ. Comorbidities in chronic obstructive pulmonary disease. Proc Am Thorac Soc. 2008;5:549-555.

22. Falk JA, Kadiev S, Criner GJ, Scharf SM, Minai OA, Diaz P. Cardiac disease in chronic obstructive pulmonary disease. Proc Am Thorac Soc. 2008;5:543-548.

23. Scharf SM, Iqbal M, Keller C, et al. Hemodynamic characterization of patients with severe emphysema. Am J Respir Crit Care Med. 2002; 166:314-322.

24. Minai OA, Chaouat A, Adnot S. Pulmonary hypertension in COPD: epidemiology, significance, and management: pulmonary vascular disease: the global perspective. Chest. 2010;137:39S-51S.

25. Thabut G, Dauriat G, Stern JB, et al. Pulmonary hemodynamics in advanced COPD candidates for lung volume reduction surgery or lung transplantation. Chest. 2005;127:1531-1536.

26. Kessler R, Faller M, Weitzenblum E, et al. "Natural history" of pulmonary hypertension in a series of 131 patients with chronic obstructive lung disease. Am J Respir Crit Care Med. 2001;164:219-224.

27. Jörgensen K, Müller MF, Nel J, Upton RN, Houltz E, Ricksten SE. Reduced intrathoracic blood volume and left and right ventricular dimensions in patients with severe emphysema: an MRI study. Chest. 2007;131:1050-1057.

28. Vonk Noordegraaf A, Marcus JT, Roseboom B, Postmus PE, Faes TJ, de Vries PM. The effect of right ventricular hypertrophy on left ventricular ejection fraction in pulmonary emphysema. Chest. 1997;112: 640-645.

29. Owan TE, Hodge DO, Herges RM, Jacobsen SJ, Roger VL, Redfield MM. Trends in prevalence and outcome of heart failure with preserved ejection fraction. $N$ Engl J Med. 2006;355:251-259.

30. Klein AL, Burstow DJ, Tajik AJ, Zachariah PK, Bailey KR, Seward JB. Effects of age on left ventricular dimensions and filling dynamics in 117 normal persons. Mayo Clin Proc. 1994;69:212-224.

31. Lichodziejewska B, Kurnicka K, Grudzka K, Malysz J, Ciurzynski M, Liszewska-Pfejfer D. Chronic and acute effects of smoking on left and right ventricular relaxation in young healthy smokers. Chest. 2007;131: $1142-1148$. 
International Journal of COPD

\section{Publish your work in this journal}

The International Journal of COPD is an international, peer-reviewed journal of therapeutics and pharmacology focusing on concise rapid reporting of clinical studies and reviews in COPD. Special focus is given to the pathophysiological processes underlying the disease, intervention programs, patient focused education, and self management protocols.

This journal is indexed on PubMed Central, MedLine and CAS. The manuscript management system is completely online and includes a very quick and fair peer-review system, which is all easy to use. Visit http://www.dovepress.com/testimonials.php to read real quotes from published authors 